\title{
FOUR YEARS OF INFORMATION EXCHANGE
}

The National Institutes of Health in the United States have for four years been running a rapidly growing system for the exchange of preprints between scientists working in biological fields. The first information exchange group, started in April 1961 on an informal basis, has now been joined by six other groups. The speed with which these networks, which have sometimes been called "invisible societies", are growing can be told from the fact that information group No. 7, barely a year old, had 1,100 members in April of this year and is expected to reach 2,000 by the end of 1966 . The organizers of the scheme are now reaching the point at which they must apply for permanent financial support for a version of the experiment which has been running, and an appropriate request has apparently been made through the administration of the National Institutes of Health. At the same time, what is called $A$ Report to the Members has been circulated by Dr. Errett C. Albritton, the director of the information exchange programme. This is valuable insight into the working of the information exchange and its problems.

\section{Faster Publication}

According to Dr. Albritton: "The overall objective [was] to accelerate the advance of medical science by subsidizing quick scientist-to-scientist communication on an experimental basis within a group of scientists (and later six more groups) in which there existed a high degree of identity of research interests". $\mathrm{He}$ argues that the informal exchange of information between scientists working close to each other in laboratories, or sharing the same coffee room, is a model for the kind of exchange of information that information exchange groups should promote. "Since taxpayer's dollars would support this experiment, the IEG had to be clearly differentiated from media of communication already serving science, and IEG's service had to be convincingly related to actual acceleration of the advance of science. The distinction between the service to science as proposed, and that supplied by journals, involved dimensional differences on two separate scales, one of speed of communication of research findings, the other of excellence of what was communicated. . . Journals sacrifice speed to achieve excellence; IEG would sacrifice excellence-if it did not already exist in a communication-to achieve speed. If it did not already exist [sic], for many or even most of the communications in this subsidized professional correspondence might be of such high excellence that the journal would require no alterations whatever. But that would be an individual matter-the IEG would have no screening or review mechanism for assuring excellence."

Dr. Albritton compares the exchange of information within the exchange groups to the exchange of information at symposia and also cites the practice of the Proceedings of the U.S. National Academy of Sciences, in which papers submitted by membors of the Academy are published without being referecd. He adds that the justification for spending taxpayers' money on such a scheme cannot simply be speed and that there must be "convincing reason to believe that the experimental operation proposed would actually accelerate scientific discovery and thus lie within the mission of the NIH". He quotes Dr. Philip Handler, one of the original sponsors of the information exchange groups, as saying that the chief object is to "accelerate the progress of scientific discovery" by updating "the frame of reference in which the scientist makes his day to day research docisions". There are said to have been two chairmen of information exchange groups who have supplied instances in which members were saved from embarking on projects because they learned, through the information exchange group to which they belonged, that the work had already been done elsewhere.

"Polls of membership by two IEG ehairmen have supplied actual instances in which members were saved embarking on a project that another member had just completed, and instances of radical revision of plans, triggered by incoming information. Dr. Handler did not expect these spectacular instances to be frequent in occurrence; IEG's main impact would lie in the more informed decisions it made possible, throughout the research area, in every research laboratory.

"Sufficient documentation does not exist as yet for an appraisal of the impact IEG is having to accelerate the advance of scientific discovery. Statistical data on the average and range of the time-span between dispatch of scientific memos from the NIH print shop and the appearance of the same research findings in print in a journal are not as yet available. But the longer that time, the more near to 'actually current' is each recipientscientist's frame of reference for his day-to-day research decisions."

On the cost of the system, the Report to Members has very little specific detail to provide. The cost for 1966 is said to be "by no means small" and equivalent to twenty average research grants. Dr. Albritton has calculated that if all the 18,000 recipients of National Institutes of Health grants were members of information exchange groups, the overall cost would be $\$ 5$ million. This, of course, is probably a figure which takes aceount of the financial economies that would arise if there were even more members -in other words the present cost per member is likely to be greater than it would be when all National Institutes of Health grant holders were enrolled.

The Report to Members points out that the seven information exchange groups are formally autonomous. "The IEG Office does the observing, but otherwise serves only as a mail drop for scientists who wish to communicate their research findings speedily to their colleagues around the world. The experiment is costly and thus must be limited. These seven groups are rogarded as a sufficient pilot run out of the 250 to 300 possible scientific groups the NIH might come to support."

Dr. Albritton's memorandum continues:

"Priority. Reference to priority in a recent memo from the writer needs elaboration. The IEG clearly has some of the attributes of a scientific society, formed, however, solely to speed communication. Basic in such a 'socicty' 
is the observance of the ethics of priority. Without confidence in such observance, no scientist would care to accept membership. When the successive IEGs were organized, each, through its chairman and/or co-chairman, adopted as one of the conditions of membership the commitment to observe priority.

"One of the gratifying findings in the experiment has been the almost complete absence of any failure to observe priority, traced in its rare occurrence to a hasty reading of a memo received. The finding has been communicated to the membership for the benefit of any of the more recent members who may have less than complete security in quick communication of their own research findings.

"Quoting Material in Memos. The consensus among the IFG ehairmen regarding bibliographie references to seientific memos may be repeated here for the benefit of the newer members. It is that inasmuch as a memo is not a 'publication' (it falls in the category of private professional correspondence), it may not be referred to in a bibliographic reference except as a 'personal communication' from the author of the memo. (It should, of course, be cited, if the writer of the published paper is a member of the IEG or has had access to an IEG memo through the courtesy of a member.) Prudence suggests that the writer of the paper [should] consult with the author of the memo to see if he still stands by the statement to be quoted. (Some IEG members make it a practice to dispatch at once to the author of a particularly interesting memo a request for a reprint of the article when it finally appears in a journal.)

"Membership Policy. Again for the sake of the newer members: Every research finding in an IEG's research area is potentially needed, quickly, by some member. If the finder is not a member, his findings are missing from the information stream. And just this much is missing from the stream's impact to accelerate research progress. Scientists not doing research in an IEG's research area belong in some other IEG, maybe yet to be formed; but scientists who are doing research in the IEG's limited area should be in, if they are capable of independent research.

"The Recent Delay in Dispatch of Memos. In the past two months the time between receipt of memos and their dispatch has been rapidly extended in the NIH Print Shop, until, in some instances, a memo has stayed in the shop as long as two months. This has been explained to us as temporary, due to a heavy load of research grants printing falling on the Print Shop at the same time as they were suffering from an unforeseen shortage of operating staff. The emergency has not ended at the time of this writing, but we are assured that they will try to move back to a week or ten days as their normal production time.

"What is the Future for IEG? The IEG remains an experimental programme. The chairmen and co-chairmen and other close observers believe IEG is here to stay. If it is, the programme will be taken out of the experimental category and will be able to extend its coverage to other research areas. However, still under consideration by higher administrators is the question whether the amount of acceleration IEG gives to scientific progress is worth the cost. An increase in speed seems a possibility; cutting costs is a possibility. Either should help toward an affirmative answer."

Dr. Albritton says that there has been an increase in the number of memoranda contributed by each member of the group as the years have gone by. He estimates that 80 per cent of the memoranda circulated at the beginning of the experiment eventually appeared in print in ordinary journals, and suggests that tho present ratio is nearer 90 per cent.

It would, of course, be wrong to think that the volume of literature flowing into the National Institutes of Health can be processed without trouble. In an earlier note headed "Memos Must Be Camera-Ready!" Dr. Albritton advised members that "the IEG Office is receiving so many manuscripts (typescripts) each week that have to have additional work before they can be printed, that we are having to make a drastic change in procedure. Hereafter, memos that are camera-ready will be processed first and rushed on to the NIH print shop, but those requiring more work will be set aside in a waiting file - to be attended to when we can get to them. It is worth your investigating whether your secretary has the erroneous idea that a typescript that is 'journal-ready' is automatically also 'camera-ready'. What we send to the NIH print shop must be ready for the camera".

This note goes on to explain that pages must be numbered, glossy prints must be mounted, and that pages that have to be turned sideways must be legible when the top is turned to the left. By the end of the year (1966) Dr. Albritton expects that the delay in processing manuscripts before sending them to the "print shop" would be a month. He follows with practical advice "Addressed to Secretaries" which includes the helpful paragraph: "Now for a suggestion that will give more 'class' to the memo, if it does not seem too complicated to you. If all tables and all figures are segregated to the back of the memo, it gives more class to the printed job if FIGURES can head a right-hand page; and the same for TABLES, and the same for BIBLIOGRAPHY. Right-hand pages are odd, you remember. If one of these headings is about to be on an even-numbered page you can prevent it by inserting a blank page, giving it the even number, and proceeding on from there".

\section{Why Not Get it to Us NOW?}

\section{Dr. Albritton writes:}

Information Exchange Group No. 1, now entering its sixth year with over 700 members, has demonstrated conclusively that research findings can be disclosed through the IEG months before journal publication, without jeopardizing priority. In fact, it is now clear, the IEG has brought into existence new and potent safeguards to priority. The protective factors seen to exist within the IEG, that do not exist outside, may be pointed out:

1. Assume that a memo by scientist " $A$ " contains a research finding that must be mentioned in a memo or published paper by scientist " $B$ ", else he fails to give $A$ due priority credit. Every scientist is motivated to respect priority, but scientist $B$ has added motivation: he has committed himself in one of the conditions of IEG membership. $B$ honours his commitment in relation to $A$ all the more in view of the fact that all his peers in the group are witness to $A$ 's priority.

2 . If $B$ 's memo should actually fail to give $A$ the priority credit due him, $A$ has the opportunity to call it to $B$ 's attention, privately, before the paper comes out in a journal. (If $B$ 's paper is already in print, $A$ still has recourse to the next procedure.)

3 . If $A$ does not get satisfaction from $B$ in private correspondence, $A$ can lay the matter before the IEG chairman. The chairman will, of course, satisfy himself that $A$ has a valid complaint, but then can privately bring irresistible pressure on $B$. $A$ also has the option of sending a memo through the Exchange.

There are now 2,500 members in the seven IEGs, and 1,200 memos have been transmitted, all priority protected. It is obvious, of course, that a paper sent through the IEG is better protected than one published without prior circulation through the IEG. Even more obvious: the earlier a paper is sent to the IEG Office, the surer the author can be that he actually will have priority. Surest of all will be the author who sends the paper through IEG as soon as the last page is pulled out of the typewriter. Waiting until it is accepted by a journal is an unnecessary precaution-the delay, even detrimental. 